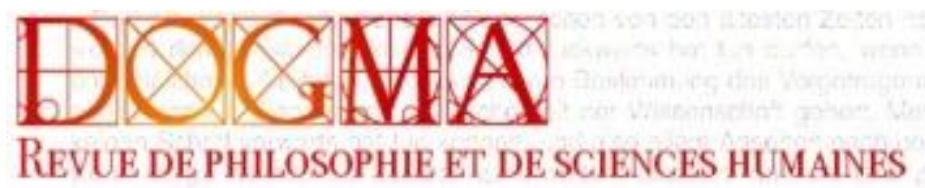

ISSN 2726-6818

\author{
UDC 416.731 .421$. \\ DOI https://doi.org/10.46805/dogma/maltsevolegpracticalphilosophy
}

\author{
Phd Maltsev Oleg ${ }^{1}$
}

\title{
Practical philosophy in the study of Jean Baudrillard's legacy: skills, education, professional environment
}

\begin{abstract}
The purpose of the following scientific exploration is to apply the heuristic memory models data to the interpretation of the praxiological results; it is focused on interpreting the legacy of Jean Baudrillard's personality, his projects, contributions to the development of philosophy and science. We analyse the issues preserved in the living memory of experts for methodological value in education and self-education, in the practice of the skills acquiring, as well as relevant skills concerning the next generations. The gnoseological concept is aimed at verifying the results of the philosophical judgment of the memory phenomenon theoretical principles toward the practice of understanding the philosophy of J. Baudrillard and his memory heritage.

In the following article, we represent the results of praxeological and epictemiological applied research concerning the memory concepts philosophical understanding following the example of studying the memory of a famous personality: a remarkable French thinker of the late 20th and early 21 st centuries, the "father of postmodernism", the author of more than 30 books which, on the one hand, caused series of discussions

\footnotetext{
${ }^{1}$ multiple Ph.D (psychology, philosophy), author, psychologist, researcher, criminologist. Academician of Ukrainian Academy of Sciences. Founder and director of The Memory Institute, Head of Odessa Regional Branch of the UAS, head of Expeditionary Corps, chairman of Odessa Photographic Scientific Society, Ukraine. Author of numerous books in the areas such as applied history, sociology, depth psychology, philosophy, criminalistics, criminology. Email: olegmaltsev@baudrillard-scijournal.com
} 
and disputes, on the other hand, awarded Jean Baudrillard the second name of "the last prophet of Europe".

According to the results of the scientific research, we shall scrutinize the role and influence of the environment and world memory "constructs" and history on the memory formation of an authentic person, his books and ideas, actions and effects of creativity, on the perception of memory content of an individual, as well as on wherewith these data may be applied in present circumstances regarding an active approach to the philosophical and practical conclusion of methodologies and educational technologies relevant and encouraging in the 21 st century.

Regarding the postulate of the unity of theory and practice, we succeeded to produce a system of practical philosophical analysis in the narrative of semi-structured interviews experts, who are followers, successors, critics and independent researchers, i.e., the "Carrier data" of the philosophical, anthropological, psychological and sociological memory heritage of Jean Baudrillard.

Keywords: memory, phenomenology of memory, philosophy of profession, education technology, activity approach, skills, heritage of J. Baudrillard.

\section{Introduction}

In our research, we demonstrate the sources as interpreted data, i.e., interview results, conducted with the expert set, whose associates position themselves as friends, followers of J. Baudrillard, or his critics, or acting as independent researchers; they complete the sources of new data, allowing one to examine the 'memory' as a distinct system of ahistorical figure following the logic of "authority - habit - training program - environment", as well as in functional research striving to identify the approach the study of personality's memory passes through the conversion steps of the data into effective skills.

To start with, we have acquired the aforementioned epistemological and axiological system of approaches to primary sources analysis. Considering the works and books of Jean Baudrillard is the original data, free for comprehension, having investigated the current literature, we dedicated the research focus to the life and work of J. Baudrillard. Hence, already at the commencement of the study of the phenomenon of character memory configurationon within generations we have concluded, that unfortunately, the data center and system of sources is not just lacking, but poor (especially in Ukrainianand the Russian-speaking segment). 
Thus, the author of this scientific investigation decided to create a research project "Heritage of the Jean Baudrillard School", within which the Memory Institute organized and conducted 25 interviews with world exceptional scientists, i.e., individuals and philosophers in science, who maintain the ground to speak of Baudrillard's life and his professional activity, his ideas and legacy.

Since the variety of global world transformations is correlated to overwhelming systemic crises and differences and the humanity transgression to a new path of civilizational evolution, which is described by dynamic processes of digitization, the expanse of hyperreality, the transformation, or merging of human activity into a virtual dimension. Prevailing trends define the prerequisites of the ontological and epistemological conclusion of sustainable social evolution vector, as well as appropriate methods for the educational improvement intended at gaining relevant skills that allow any person to achieve his goals and results.

'The results of the individual' - this is one of the fundamental categories, which form the basis of memory about the personality. Since the object of interpretation is the results of the activity of the personality, i.e., the French philosopher Jean Baudrillard, and the subject is his legacy preserved in living memory of experts, the basis is represented with his finished works and concepts, expressed in many books ("Simulacra and simulations", "America", "Perfect crime", "Transparency of Evil", "Fatal strategies" and others). Nevertheless, the philosophical judgment of the thinker's results outlined in the structure of books, entries, articles, interviews, etc. is not complete, since it is only one block of data: and data, which personality revealed in the kind of activity results: documentary, photo- and video-sources in the passage of life and activity. Hence, no less significant is the subjective system, the people who have been familiar to J. Baudrillard, especially personally.

The purpose of our scientific research is to apply the heuristic memory models data to the interpretation of the praxiological results; it is focused on interpreting the legacy of Jean Baudrillard's personality, his projects, contributions to the development of philosophy and science. We probe the issues preserved in the living memory of experts for methodological value in education and self-education, in the practice of the skills acquiring, as well as relevant skills concerning the next generations.

The praxeological concept concerns documenting the results of the philosophical judgment of the memory phenomenon theoretical principles toward the practice of comprehending the philosophy of J. Baudrillard and his memory legacy. According to the 
postulate of the theory and practice unity, which is a significant philosophical and methodological principle, we assume it is relevant to determine the logic of our research, based on information of praxeological research of heuristic paradigms of memory, credible and effective for the research of questionable and unknown aspects of personal education and acquisition of substantive skills.

\section{Materials and methodology}

Following the principle of unity of theory and practice, we conducted a system of philosophical analysis in the application of semi-structured interviews experts, who are followers, successors, critics and independent researchers, i.e., the "Carrier data" of the philosophical, anthropological, psychological and sociological memory legacy of $\mathrm{J}$. Baudrillard, the 'productive' figure in history, who for a reason is also the legend declared to be the "European last prophet".

Regarding the activity approach, we have involved works of academician G. Popov, in the tradition of his school and solidarity with his concepts of activity approach to the consideration of generations' memory. Thus, we interpret and analyze practical lessons in teaching and educating relevant skills in the individual, verified by the requirements of society. Thus, in the represented article, we applied a theoretical model of ontological and epistemological recognition of the potential result of the heritage of the figure in history in memory of the next generations (through the prism of the activity approach), i.e., the heuristic model of G. Popov, termed "model of dynamic memory blocks", consisting of four blocks (Popov, 1949).

Qualitative functional philosophical recognition of the fundamental postulates and attributive aspects of this model is also outlined in this article. In the future, analyzing the concept of the theoretical model, as it contains an ontological, epistemological, axiological and praxeological aspects, we applied these aspects to the memory heritage of object of our study - the heritage of Jean Baudrillard, for the purpose of practical interpretation, and validation of this model and axiological judgment of value and significant aspects of the heritage of $\mathrm{J}$. Baudrillard in the sphere of meta-theory, self-study aspect and education in terms of activity approach, taking into account the level and order of XXI century tasks.

As the followers of the schoolings of Academician G. Popov, we experience the judgment of the scientist, the author of the concept of memory and the constructor of the heuristic model of memory formation; we also consider, every person is known "by his deeds". Moreover, we outline, the axis for the memory configuration is the resulting 
scope of personal activity, the one achieved in his lifetime, gained through the interaction with society and the external environment, taking into account changes in spacetime terms.

The meaningful methodological vector of the memorable component essence formation of the heritage of an individual's work and his activity, in our belief, is the environment in which the object of study philosophized, created, and converted events in life. The 'environment' acts as an objective category, by inquiring which, one can determine the parameters and prerequisites of the speaker, moreover, the ideas, changes and aims that directly influence the formation of the personality's views, his approaches, and so on, i.e. the outer or external issue (society, various reference groups, etc.).

The memory studies regarding Jean Baudrillard's legacy in a semi-structured interview are based on the following basic provisions: originally, since in the philosophical study of methodology the core principle of analysis is the principle of efficiency, we chose to deal with our scientific intelligence with primary sources. By primary sources, we mean not only the works, books by J. Baudrillard, interview materials, recorded through his life, those are documentaries about the object of research, but also the outer circle of people, who knew Jean Baudrillard personally. Therefore, it was resolved to analyze "living memory" about the legacy of J. Baudrillard.

The research of memory human heritage is customarily carried out on the examples of works and "traces of memory", which the man left behind. Such a "mine" of factual material is a value for the study and understanding of heritage by future generations. (Kurdyumov \& Samarskiy, 1989). Yet, in our research, we have examined the questions of a complicated status: how memory about a character (who has left his imprint on history by his results, associated concepts, innovative ideas, practical tools, and technologies) affords future generations to learn from living "history lessons"? Is it proper to limit the conclusion of the phenomenon of memory, for instance, about the philosopher and thinker, within an approach adhered exclusively to his works and written sources studies?

Regarding the postulate of historical and logical unity, we adopted a qualitative method of semi-structured interview, following the reasons: to begin with, it is a philosophical study, hence, we are involved in the meanings and interpretations of experts, scientists, deeply acquainted with the legacy of J. Baudrillard, that is the reason we do not prefer mass, quantitative research. 
Secondly, heritage information of Baudrillard's character has to be represented at a high professional level, since we are interested in complex mechanisms of representation of memory; the third aspect is, we kept a semi-structured interview approach, that allowed, on the one hand, to ask the most regular questions about memory and heritage of J. Baudrillard (The legacy of the Jean Baudrillard school); on the other hand, semistructured interview allowed listening to the expert without being accused of prejudice, at the same time maintaining the logic and course of our interview.

\section{Results and Discussions}

The logical model of praxeological and gnoseological judgment of the memory phenomenology in 1949 by G. Popov embodies the following scheme. To begin with, the outer world is a mirror of human memory, following this, individuals dos not invent anything, but receive data from memory. Secondly, this logical approach may also be identified and used in the study of human mechanisms learning. According to the philosophical analysis of the author, the child also learns to interact with the external environment (Kurdyumov \& Samarskiy, 1989). Besides, any person demands demonstrations and 'live patterns', i.e., some figures or personalities, that fit possible authorities in the process of learning and professional skills obtaining.

G. Popov conducting the memory research and its projections on the external level concluded the hypothesis, that everything a person views around him are the results, "pulled out", taken away from human memory. (Popov, 1949: 46). G. Popov defined, as well: “... everything, that exists externally, is a display of human memory” (Popov, 1949). In the memory phenomenology G. Popov has determined the following postulate: 'the outer world is a mirror of human memory'. Therefore, the man does not invent anything, as he regains data from memory (Popov, 1949: 44). Regarding this principle, one of the key strategies to the study of memory is the so-called method of external analysis. For example, if a person writes something down, photographs or paints, thus he makes a separate block of memory, that is similar to be 'taken away' from him (external memory data block).

Furthermore, Gregory Popov (Popov, 1949), by explaining the theoretical model of human memory, introduced and implemented the concepts "dynamic" and "static" memory blocks. The explorer shortly explained the interaction of the data mechanisms of the two blocks of memory. As a result, we can trace on a logical illustrative model in the unity of two aspects: dynamics, future-oriented (dynamic memory block), and one directed to the past (static memory unit). Since one of the goals of human skills is to 
achieve the future (that is, an adult understands the desired representational future must be achieved somehow, and this demands effective skills and actions) (Kagan, 1974); the author of the research recompenses exceptional attention to dynamic memory blocks. Besides, we recognize the central attributive features of the four dynamic blocks of human memory (Popov, 1949).

Dynamic memory block "circus". The key attribute characteristic of this block is skill (Popov, 1949: 47). It is in the "circus live skills": the most unusual, the most agile, the strongest people demonstrate their skills to the public: trainer skills, balancing skills, weightlifter skills, trickster, etc. The key attributive characteristic of "heater" block is the "role" (manifested in the activity as the ability to choose roles, embody them,"play" in life "and thus achieve results and success in business) (Popov, 1949: 47).

Therefore, in courses of learning the processes of this block of memory by "university" we expect certain institution, in which there is a set order, there are consultants, educational literature, and more importantly, the methodology. There are people, developing, receiving this knowledge, since there are seminars, offsets, etc. Overall, this data concurrently fits the block "university". Key attribute characteristic is methods and training program (that provides one an answer to the question "how to do something").

The following block G. Popov described as "religious institutions": "We will not name it a temple, church or any-what other institution. By this block model, we suggest the institutions of a religious nature". G. Popov did not require a specific term for that; he practiced the collective metaphor of "religious institutions". Therefore, following logical argumentation on this topic, we should consider, each person holds his own exceptional religious knowledge, data, reviewers, mechanisms, and the order of their use in cognition of the external world, its nature, pictures of his environment as a system. The key characteristic of this block is the mechanism (Popov, 1949: 48).

These four blocks of memory: "circus", "theater", "university" and "religious institution" signify dynamic memory blocks. Overall, these blocks indicate differences in the system of the human worldview, in its pursuits and actions. In the implementation of these memory blocks events take place, the state of affairs changing. And each person possesses a configuration of these 4 (four) memory blocks.

According to the philosophical representations of Academician G. Popov, which are the issue of epistemological and praxeological conclusion of the environment and contents of memory, as well as the sources and criteria for the operation of the mechanisms of memory; based on the heuristic model of memory, we shall discern the logic of controlled acquisition of professional skills. 
Heuristic model of dynamic memory blocks and the concept of activity approach undeviatingly ascertain the value and methodological functional significance of this philosophical judgment, since 4 key categories "skill-environment-training program-authority «form a system of education and self-education of a person on the way to his professional development" (Popov, 1949: 50). In other words, in the process of life and activity, i.e., in the process of self-training and self-education there is a "skill" - the category 'constructed' as a result of the interaction of four dynamic blocks of memory, i.e., the "theatre" - "circus" - "Religious building" - "Educational institution" through the use of education / self-education of the managed model "authority - environment

\section{- training program - skill”.}

Therefore, as a step of our scientific analysis, we outline the results of the research of the memorial figure, i.e., the world-famous thinker and philosopher Jean Baudrillard within the logic of the heuristic model of the structure of dynamic memory blocks including those constructs and components, which allow one to control the mechanisms of these memory blocks consciously, thereby enriching the personal set of skills and abilities (Popov, 1949).

On the example of the memory about Jean Baudrillard judgment through the use of the epistemological concept of "authority - environment - training program habit", we may consider effective examples which enrich the modern recognition of it, how to learn "history lessons" and learn from professionals (even if they are no longer physically present in our lives, still the peculiar memory of them is maintained).

Six interviews are analyzed in detail in our scientific investigation. Experts interviewed were requested to speak, were judged according to the following criteria: intellectual level and education, the presence of deep works on the theoretical heritage of J. Baudrillard, and (or) personal communication with J. Baudrillard, experience in philosophy, methodological and theoretical understanding of scientific works. The author supported the experts with the assistance of an associate of the Memory Institute, who holds professional vocabulary and language of communication interviewee (Maltsev \& Lepskiy \& Samsonov).

As a result of praxeological analysis, four groups of experts were classified (The legacy of the Jean Baudrillard school):

1. "Students" who personally knew J. Baudrillard and gained knowledge both directly and indirectly through co-working, interviewing and so on. 2. Followers of $\mathrm{J}$. Baudrillard, who did not know him personally, however studied and researched his works, concept and developed his experience. The study of such material allows us to 
comprehend contribution of Jean Baudrillard as a philosopher and thinker. 3. Critics of the works and views of J. Baudrillard - opposing side, which also acts as a 'force' that comprehends and rethinks the role and significance of the results of individual activity in world history. 4. Researchers of J. Baudrillard - the independent experts, who did not know J. Baudrillard personally, do not consider themselves his supporters and followers, however, they might provide the results of their own understanding of ideas, concepts and innovative developments J. Baudrillard and describe their potential significance in terms of application in solving life problems in a dynamic environment of the XXI century.

Experts (The legacy of the Jean Baudrillard school):

1. Dr. Arthur Kroker. Canadian author, editor, educator and researcher of political science, technology and culture. In addition to being a Professor of Political Science at the University of Victoria, Kroker serves as director of the Pacific Centre for Technology and Culture (PACTAC), located at the university. He is an editor of academic journal Ctheory, an international journal of theory, technology and culture.

2. Dr. Athina Karatzogianni. Associate Professor in Media and Communication at the University of Leicester, UK. She has an extensive record of publications and citations in disciplinary, field-specific and cross-disciplinary research outlets, and has demonstrated sustained success in securing research income from Research Councils UK and the European Commission. Her most recent book is (2018) Platform Economics: Rhetoric and Reality the "Sharing Economy".

3. Dr. Bernardo Attias. Professor in the Department of Communication Studies at CSUN. His research focus emphasizes cultural approaches to communication studies as well as communication-centered approaches to cultural studies. The emphasis of much of his work is on the political economy of mass-mediated events through the teachings of Michel Foucault and Jean Baudrillard.

4. Philip Beitchman. Professor Philip Beitchman teaches at Medgar Evers College (CUNY), translator of Baudrillard's books such as "Simulations" and "Fatal Strategies". $\mathrm{He}$ is the poet, researcher, translator, writer. Author of books: Alchemy of the Word: Cabala of the Renaissance; The View from Nowhere: Essays in Literature, Mysticism and Philosophy; The Theatre of Naturalism: Disappearing Act.

5. Dr. Tim Otto Roth. German conceptual artist, composer and scholar. He develops a physical approach focusing on light phenomena in nature. In 2015 he published the “Cultural History of Shadow Pictures". He interviewed Jean Baudrillard about photography ("The Art of Disappearance") 
6. Dr. Thierry Bardini. Interview 'J. Baudrillard, cyberculture, and a system predicting the future of humanity'. Thierry Bardini is a French sociologist and professor at the University of Montreal, Canada. Bootstrapping: Douglas Engelbart, Coevolution, and the Origins of Personal Computing. Junkware

As a result of our scientific research, we will consider the role and impact of the environment and "constructs" of world memory and history on the formation of memory about an authoritative personality, his works, achievements and 'fruits' of creativity, to determine the content of memory of personality, as well as the ways these data can be used in modern conditions in terms of activity approach (Kagan, 1974).

\section{'Environment' issue is the first one to be analysed within our research.}

From the epistemological segment, illustrating the influence of Jean Baudrillard's philosophical ideas on learning the future and predicting future trends (dynamics of the "future in the present") Arthur Kroker, writer, Professor of Political Science and Head of the Scientific Center of Technology and Culture claims in general, at the moment the modern world has been completely defined by Jean Baudrillard. And he prophetically identified two main movements, what the postmodern society of the future will look like. Firstly, it is a political economy. Jean Baudrillard best explained it in full in his book 'The Political Economy of the Symbol', i.e., the way the "digitalization", exchange and use of values might take place.

The second area of philosophical ontological and epistemological perception of the future, according to the comments of A. Kroker, Jean Baudrillard has claimed, the social masses were always driven by a fatal death. This is their main engine, about which Nietzsche spoke, once again demonstrates us, how much "..technology is rapidly gaining scale and how this world is fully technologized, in the end-finally coming to collapse".

Afterward, in addition to the variety of the two ontological principles of discovering the system of formation of the environment of the future, A. Kroker attaches the third principle, i.e., the theory of simulation, while the fourth is the principle of cultural temptation. Temptation is very powerful, for Baudrillard. He determined all things that a point in time may concurrently turn the other way.

The environment of formation of actual experience can also be the works of an authoritative figure: books, articles, notes and other documented data. In particular, independent researcher Athina Karatzogianni was able to create her own concept of cyberconflicts, by studying the books of Jean Baudrillard and axiologically analyzing the concepts, proposed by him. So, answering questions: "And why did you choose the works 
of Baudrillard, but not some other sociologists, philosophers; why taking Baudrillard's approach?"

Athina Karatzogianni, researcher, author, lecturer at the University of Leicester (United Kingdom) explained: "Firstly, when I was writing my doctoral dissertation, I used Baudrillard a lot, since 2002 till 2004. I was just curious about what he writes about violence, since I studied cyberwar politics; then I was interested in his work. Well, through his work, I studied globalization and ethnic internet conflicts, hackers' issues, etc."

Furthermore, she explained she created her own theory about cyber conflicts, using three aspects. First - a new approach to the media, second - social movements, third international conflicts. It was here that Baudrillard helped her, plus reflection about the media, about digitalization, about anything digital and symbolic, i.e. A. Karatzogianni finds Baudrillard's ideas are rather beneficial, emphasising the books "Simulation and simulacra", "Gulf War did not take place", "Spirit of Terrorism" and "Symbolic Exchange and Death" as the gnoseological source.

The heritage left by the French philosopher, according to the profound principle of the unity of historical and logical could be viewed as a data environment, that serves as a catalyst and reference in the praxiology of ideas, concepts and answers to current urgent questions in the context of the developing XXI century (Kurdyumov \& Samarskiy, 1989).

Considering Baudrillard's legacy as an environment of judgment and analytical study, Bernardo Attias in his interview explains he did not inquire about all the works of Baudrillard, but most of them. In general, he attempted to look at Baudrillard with a wide eye, since he required to study the whole history of Baudrillard, starting with 1960$\mathrm{s}$ he took his philosophical route, whereby his approach has changed in 70-s, or when his book "Simulacrum and Simulation" was published in 80-s. Furthermore, Bernardo Attias carries a historical classification of the development of scientific concepts and works of Baudrillard. That is no longer a direct sub-active characterization of Baudrillard as a figure, but his legacy is considered. We would like to demonstrate this issue within the interview fragment:

Bernardo Attias explained, Baudrillard's legacy could be historically divided into 4 intervals, on 4 event groups, or 4 groups of philosophical analysis. The first stage, Baudrillard was very close to Marxism, to semiotics, as at the first stage that he pays great attention to advertising, explains the society creates a need and when we buy an item, at the time of purchase we consume all the code (Lesch, 2003). 
'In the second stage, of course, me and many other scientists would dwell on his work "Symbolic exchange and death», since during this period he begins to talk more about hyperreality, about endless semiosis and psychoanalysis. I assume, he was extremely interested in psychoanalysis, he was interested in this even in 60-x years. and psychoanalysis greatly influenced him'.

In the second period there is a lot of talk about death and how death is a kind of motivator for something-either. B. Attias outlines the third period at the beginning 1980 year to the middle 80-x. It starts with a simulation, including the book "Simulacrum and Simulation" and "Fatal Strategies"; it is at this point that some scientists, started to perceive and consider Baudrillard as a kind of elite anti-intellectual. In interview B. Attias continues: "They think wrong, claiming Baudrillard celebrates or rejoices in terrorism. Why else do some people consider it anti-intellectual - because, when Baudrillard talks about the simulation, about semiotics, he thinks, that this world's fake".

From the standpoint of ontological and epistemological aspects of the analysis of 'the-future', scientist, representing the essence of the fourth stage, explains, that in this sense he does not have much knowledge here, however, he believes, that this is a certain period of philosophical understanding and creativity of J. Baudrillard, associated with his book "America" and "Cold Memories". B. Attias highlights the fourth period within the essay "Spirit of Terrorism", that he wrote in 2001.

According to Bernardo Attias, Jean Baudrillard wrote about America, the French thinker also wrote about utopias and a certain 'telemorphosis'. Based on this epistemological and ontological classification of study and understanding of the concepts of J. Baudrillard by his follower B. Attias claims, Jean Baudrillard was especially critical in interpreting the vector of degradation of human perception in the XXI century, recording the most significant concepts of obstacles and dependencies, as well as tools, applying which a person is involved in effective self-realization, as the instrument is the key to achieving results. Furthermore, the instrumental set allows a person no longer depend on the courses of irregular simulation environment, as well as to fit a self-sufficient object of his life, but not a "product or consequence of hyperreality".

Interpreting essential ideas and concepts, i.e., a subject of philosophical reflection in the ontology and epistemology of the masses, to the question "If we count the most crucial Baudrillard's ideas, what would they look like?" Bernardo Attias represents the first idea, i.e., the "silent majority", as Richard Nixon wrote about it. He believes it is extremely significant, that the masses actually accept a simulated society; since the decision is produced by a silent majority, about which we know nothing. The second idea 
concerns simulation, hyperreality, and how Baudrillard was influenced by Georges Bataille. Third is a system of things and critique of the political economy. The fourth idea is the fatality of strategy and terrorism, and then, 'whatever a revolution is forcing the system to move faster and show its genuine face'.

The pieces of the interview outline examples and confirmation of the fact, the memory, created by man in history, is modified for future generations into a data environment, investigating and critically comprehending which is conceivable not only to know the preconditions and ideas of the past, but also the present, its 'total picture' as well as a potential picture of the future today.

This example also refreshes the fact, the figure of Baudrillard in the science of memory clarifies issues of critical thinking about the consciousness of the future, awaiting humanity (Baudrillard, 2017). Furthermore, we admit it relevant to mention, Baudrillard was awarded with a "second name" of "European last prophet". The study of approaches and concepts, explained in his works is one of the most crucial fields and insuring data environments for further research in social philosophy, anthropology, forecasting, and modeling of the future, as well as in other scientifically-applied fields (Bauman, 2004).

The next structural part of our study was the problem of authority (Popov, 1949).

Analyzing the philosophical influence of Baudrillard's works on the mass and collective consciousness, in terms of epistemological and axiological understanding, the follower Philip Beichman speaks: "I feel, when it comes to a writer like Baudrillard, his goal was to make readers think, create, question some things. I believe Baudrillard is a 'continuation' of such people like Spinoza, Socrates, Kierkegaard. For me, Baudrillard is one of them".

This explaination of F. Beichman immediately guides to the role of Jean Baudrillard in his memoirs to 1. a potential authoritative figure (in terms of the structure of the memory unit of the generic concept according to G. Popov), 2. to a driving figure of the hero, catalyst who promotes critical and rational reasoning about their own future and destiny (the context of the archetypological block of memory (Szondi, 1956); and 3. in) to a potential figure of the prototype block of memory, responsible for the construction and formation of a philosophical worldview in space-temporal dynamics of self-realization of future generations (Popov, 1949). 
Furthermore, following the profound principle of efficiency, F. Beichman also joins, Baudrillard can be interpreted differently. For example, there are two books, which interpret Baudrillard completely differently. In the first book, he is seen as a left-wing revolutionary, and in another book, he is not considered like this.

In terms of study and review of trends, defining the formation of an authoritative figure as an element of the prototypical environment of memory, we would love to mention the peculiar position of Arthur Kroker, since he explains Jean Baudrillard considered, recently we faced the world of the absurd. Moreover, it is present everywhere: in modern politics, in the modern economy, etc. Baudrillard, if one can say so, was an "artist" of pataphysics, and believed, that power as such has ceased to exist. In fact, there is this constant absurdity, we witness with our eyes.

Regarding the fragment of the interview, it is sound to render a conclusion, in terms of research on the activities and contributions of Jean Baudrillard, this figure is not only prototypical (a kind of «prophet», interpreter, competent to pay attention to contemporary trends in order to understand the future), but also trustworthy figure skilled to conduct complex philosophical categories (including an interdisciplinary approach) (Popov, 1949).

Bernardo Attias, Professor of the Department of Communication Research CSUN, who teaches the teachings of Michel Foucault and Jean Baudrillard, to the question: "From your point of view, what is most interesting about Baudrillard?" in his reply claims Baudrillard's interest is in that there is something prophetic in it. Besides, he wrote in 1960-s about advertising, popular culture, the media; moreover, everything he predicted, soon after happened and occurred. 'Including what he said in 70 - 80-s for politic and the crisis in the media (which is now taking its place), everything came true'.

To the next question: «Can we say then Jean Baudrillard was primarily a sociologist?" Bernardo Attias explained: one may call him a sociologist and it that will be attributed to him by right, it is still the question of semantics. Personally for B. Attias, Baudrillard is a sociologist, researcher and a man, who was engaged in scientific researches. We could represent a conclusion from this fragment of the interview we deal, on the one hand, with a sample of subjective perception of the figure of J. Baudrillard, and on the other, we observe this figure is remembered and characterized by B. Attias as a specific professional role (which corresponds to the attributive characteristic of the dynamic block of memory "theater" characterized by outstanding skills (for example, prognostication, which leads us to the skill issue, i.e., the key attribute characteristics of the memory unit "circus"). 
Moreover, Jean Baudrillard did not use numbers and statistics (except, Consumer Society concept, within which he was pushed to use some statistics and numbers to illustrate his analysis). The point is the way the media provides information to people, the way the latter absorb information, overall, it is hard for them to analyze it. Baudrillard believed, there were two obligations on language stages: first one require visual analysis of the specifics, singularity of the issue; the second requires a person to analyze the current situation at this period of time (that idea is manifested in the book «Simulation and simulacra»).

Study of tactics expressed by Jean Baudrillard's as well as his research activities in the field of forecasting, description of current skills, his ability to draw conclusions and make unmistakable decisions, including the lack of reliable data, overall, it is significantly crucial and consistent within the circle of philosophically-practical tasks. The figure of J. Baudrillard, in our opinion, is truly a figure of authority, due to the availability of forecasting skills and perception of future trends. Improvement and implementation of quality methodological programs that take into account the practice of efficient philosophical research today, in terms of post-pandemic, grow even more relevant.

A significant part of the study in a semi-structured interview was an optional step in the study of the characteristics of works and personality J. Baudrillard, i.e., is the issue of training program.

Baudrillard's works and his philosophical legacy stimulate not only a rethinking of concepts, but also to independent rethinking and self-learning in terms of forming their own "set of tools», about which we will speak in more detail later. Explaining the influence of the past on the development of the concepts of Jean Baudrillard, Thierry Bardini in an interview points out, Nietzsche's ideas were close to Baudrillard, and as Nietzsche said, humanity is a disease for the earth, respectively, humanity could be considered as a virus, as a skin disease. Gilbert Simondon is a French philosopher of the 50s and 60s of the last century, his ideas are reflected in the ideas of Baudrillard. Hence, Baudrillard's ideas, according to T. Bardini, are truly significant, and they are combined with his understanding and the philosophy of Simondon (The legacy of the Jean Baudrillard school).

Thierry Bardini, explains like Baudrillard, he was involved in sociology, but he did not acknowledge himself as a sociologist. 'At first, I became a biologist, then I studied sociology, and already in the third stage, I matured as a scientist in the field of communications. Now put it together, mix it, and you get that look'. Furthermore, he adds, 
by the end of his life, Baudrillard did not require to be named a sociologist or philosopher since he generally viewed himself as a photographer (Maltsev \& Lepskiy \& Samsonov). This, among other things, was a manifestation of his modesty. However, at the end of his life, he listed separate sciences, this manifestation, firstly, of the hyperreal world, and secondly, the application of separate scientific disciplines will not help humanity.

Characterizing the influence of the spatial dynamics of the integration of the scientific apparatus, Thierry Bardini highlighted the significance of the interdisciplinary approach used in Baudrillard's writings. As one can regard, while interacting with the scientific environment, Jean Baudrillard adhered to the same integration ideas that had been tested by G. Popov and L. Szondi 50 years before, namely: an interdisciplinary approach based on the main philosophical principle of objectivity, as well as orientation on the achievement of research goals and gaining results (Popov, 1949; Szondi, 1956).

By this point, we can also point to the praxeological value of Baudrillard's regulatory concept, who developed and applied heuristic models and epistemological instruments. That also serves as a prerequisite for the formation of a review series in memory, functioning with the heritage of the Baudrillard school (that is, they determine the formation of the instrumental basis and understanding of mechanisms for solving problems in the process of life and activity).

To the question: "What do you think if a person studies the works of Baudrillard, what will one be able to learn, from your point of view?" Athina Karatzogianni assumes a person can learn about symbolic violence, about the economy, which follows Marx, one can realize, how production and symbols relate to each other, how the signs relate to production. Examining the demands of the environment and recalling the "rules of the game" in the geopolitical arena are changing, A. Karatzogianni continues: "Baudrillard wrote in his book, "only death can escape the code, so as not to be inside the code". At the moment, capitalism, if we take it as code, feels the problem, this huge number of deaths is a problem for it, they are trying to control somehow (Baudrillard, 2015). 'The problem itself we are talking about is extremely sharp'.

Furthermore, we come to the conclusion a scientific research of the place and essence of philosophical, economic, social and anthropological concepts, introduced by Jean Baudrillard, especially in understanding the tactics of action to mitigate the effects of a pandemic year, acts as a promising and significant research field for the development of logical and tactical models of the following measures, aimed at stabilizing the world economic and geopolitical situation. 
As a relevant perspective for the study and field of philosophical judgment of Baudrillard's legacy, as well as a source of attaining an effective training and self-study program, we reward attention to practical and at the same time philosophical application of the camera and the act of photography, introduced by Jean Baudrillard (The legacy of the Jean Baudrillard school).

Jean Baudrillard himself (and this is confirmed by researchers and followers) regularly drew a parallel between the books he wrote, and photos he made, discussing that principally it is the same action (Maltsev \& Lepskiy \& Samsonov).

Thus, an act of world cognition through the experience of meaningful photography by Baudrillard is one of the relevant skills for the contemporary of the XXI century in terms of self-study, comprehension of modern trends, orientation in a changing environment and the development of the ability to see the «essence of content without a wrapper»».

As a result, we shall analyze causal symbiosis, that merges the figure of Jean Baudrillard into a «prophet», which allows people to perceive they are unable to notice due to their connection to hyperreality (Baudrillard, 2017). That is, in one case, this symbiosis may be an identity, and otherwise, a philosophical act of vacuum, which forces a person to fill it with their thoughts and ideas. Baudrillard in every act of photography aspires to encourage people to think and act consciously. Thus, photography is an environment of scientific knowledge and the act of training with a camera (like make every picture as the best one, since photo = result). Camera is a training apparatus; as an independent issue to practice, it pretends to be an effective stimulator to accomplish results (the latter is dedicated to the "skill" category).

The next dynamic part of our praxeological judgment is a skill.

In philosophical understanding of the legacy of Jean Baudrillard and an explanation of the differences between the tactics of action and the implementation of the skills of this authoritative figure from others, revealing, what is distinctive about the figure of Baudrillard in the structure of scientific activity, Thierry Bardini noted the following. Baudrillard was very different from other sociologists at the time because not only analyzed, not only worked with numbers and statistics, he had a completely different approach. He analyzed the world more widely, he analyzed trends, facts - and he had some intuition. To provide an example: now the coronavirus is everywhere, and all people are trying to mathematize and find some standard, simulate some rules, to which everything will be subordinated. All countries of the world act in the same way. However, Jean Baudrillard would never do that, since he understood every country and every nation is 
different, as it is unique. Aiming to the mentality element, Thierry Bardini recognized the features of the common perception of the effects of the environment on the dynamics of human activity. That is also described as the philosophically-sociological difference of individual scientific approach of J. Baudrillard in contrast to the mass mathematicianstatistical approach to operating with scientific data.

Moreover, according to the logic of G. Popov, such a systematic approach is not compared only with the controlled ability to work with the mechanisms of intuition, but also to represent the courses of the environment and the impact of environmental requirements on the mass and collective awareness of processes, befalling today (Bauman, 2004).

Pandemics also updates this approach since various people share the need to forecast the conditions of "post-pandemic world". Assuming these requirements and demand, we can define the works of Jean Baudrillard, who philosophically embraced the world after global catastrophes (and simulated disasters), in the coming decades, interest in the practical direction will advance, as to memory and treasuries scientifically-applied thought, which allows one to move in circumstances of ambiguity demanding daily results in the process of course and activity (Baudrillard, 2006).

Of particular interest is this aspect of the contribution to world memory, is the phenomenon of "Baudrillard's photography". Baudrillard considered the very skill of photography as something more 'vast' and functional than the act of engraving or the physical act of pressing a button. Further material is provided following the interview with researcher Tim Otto Roth who personally interviewed Jean Baudrillard (Maltsev \& Lepskiy \& Samsonov). Replying the question "Why did you talk about photos?" Tim Otto Roth explained the point is, his core interest is not in photography, but in what is the nature of the image. And that's why photography is one of the elements researched. 2000 - 2005 Tim Otto Roth organised a huge number of interviews with many scientists of different disciplines; those who studied the humanities, the theorists, too. I was curious what is an image».

The next fragment explains, “...one of the reasons for this was I did not find any information on the subject of Baudrillard's photography. The point is when we talked, the goal was to understand how his photographs relate to his ideas and to his theories. And what is interesting about this interview - at the same time we questioned his own ideas".

According to T. Otto Rott the act of photographing, in the first place, is a meditative act rather than communicative. There is a moment of contemplation, the most intimate 
moment, a so-called secret game. Photography is a kind of escape creation, eliminating the value (Baudrillard, 2015). Moreover, it comes from a very specific intention: do so, to the present world (our current world) disappeared, and play it to the very end. This is the art of extinction. This applies to our world, as well as if we are talking about other cultures.

Baudrillard believed photographers are the "technology operators". As well as the camera can be a technology in the hands of the photographer and one is only the operator of this technology (The legacy of the Jean Baudrillard school). However, Baudrillard himself never photographed like that. Even driving a car Baudrillard remarked, he does not consider himself a 'technology operator'. A car for him was a certain instrument training him to drive it perfectly. In fact, according to Baudrillard, the photo camera should encourage the person to take great pictures. The camera should "force" one to become a great photographer. And this is one of Baudrillard's profound dogmas: philosophical relation to the camera, which will make one an exceptional photographer; same 'attitude' to the car, which will help one drive it flawlessly; i.e., the choice of tactics, which will help a person triumph (Baudrillard, 2006).

Tim Otto Roth claims, understanding Baudrillard's theory is similar to learning the way he takes pictures. "So, his photos are not bad, however, they are not phenomenal. That is, these are good amateur photos. Still what's interesting: if it comes to photographs of Jean Baudrillard: (...) he studied media theory and what impact image possesses and that is really interesting; moreover, everyone is trying to understand his theories, looking at his photos" (The legacy of the Jean Baudrillard school).

Overall, we might achieve within the analysis of the interview with Tim Otto Roth, the purpose of photography according to the philosophy of Baudrillard is to make "the present world disappear", like to "play to the end". And this should be reflected in the photo (Baudrillard, 2015). How is this accomplished? Hence, according to the interpretation of J. Baudrillard in an interview, the photography makes the world disappear, because a person sees only a fragment of it (its part) - i.e., the whole other world disappears. The departure to the very end demonstrates the opposite of the existing «hyperreality, simulation and illusion crashed on this photo» (Maltsev \& Lepskiy \& Samsonov).

Regarding the results of our philosophical understanding of "living memory" about J. Baudrillard and his legacy, we shall represent the key subjects of philosophical consideration.

Following the principle of unity of theory and practice in terms of activity approach we assumed a model of attributive characteristics and dynamic components of memory 
reflected in the concepts of "skill", "role", "Training methodology and program", as well as the "mechanism". This task is aimed at ontological and epistemological understanding of the logic of dynamic memory blocks, i.e., human interaction with the external environment and its requirements, which contributed to the epistemological understanding of the logic of "environment-habit-training program-figure of authority". The praxeological concept is relieved for verifying the results of philosophical interpretation of theoretical models of the memory phenomenon in the practice of understanding the philosophy of J. Baudrillard and his memory heritage.

\section{Conclusions}

Analysis of memory heritage J. Baudrillard on the basis of the praxeological paradigm "authority-environment-training program-skill" contributes to the understanding of the philosophical concept of a prominent thinker, and directly determines the vector of effective perception and data processing, represented by inheritance, in the light of the tasks and requirements of the XXI century through the prism of activity and the need to predict and timely receive relevant skills.

The increasing impact of axiology and the reflection of the mechanisms of memory in discovering the value of J. Baudrillard. The next judgment is, Jean Baudrillard becomes a prototype in social memory, i.e., an authoritative "timeless" figure, who presents the basic definitions of spatially-time category "hyperreality", as well as describes the logic and features, shows in his works how not to live as a consequence of simulations and hyperreality - all this indicates relevance, specificity and integrity of memory about the legacy of J. Baudrillard. Contrasting aspect is, in this case (according to Popov's categorization), that is also a potential figure of the authority configuration model, philosophy of which efficiently supports a person to achieve results and accomplish goals in his life.

Hence, following in our scientific exploration the information, represented by experts, disciples, independent researches and followers of the school of J. Baudrillard, in the context of memory, we should recognize the figure of Jean Baudrillard as a prototypical figure in the XXI century - including, based on the level of criticism of his opponents about the activity procedural significance of the inheritance of J. Baudrillard.

The most significant aspect in the praxeological and axiological section of our scientific analysis has been the activity approach; epistemological and axiological aspects of the analysis of the philosophical heritage of the school J. Baudrillard also actualizes current philosophically-methodological researches and perspective researches aiming at 
developing programs and systems for training experts and professionals, skills and abilities which meet the requirements of the environment and the XXI century, which is dynamically changing been thus characterized with continuous processes of digitalization, "loss" of activity attributions merging into "virtual space", replacement of physical socially-communication space space internet-resources and social networks, as well as "extending hyperreality", i.e., the concept introduced by the prominent French philosopher and sociologist Jean Baudrillard.

\section{References}

Bauman, Z. (2004). Globalization. Consequences for man and society. Moscow: Publishing House "The Whole World». 158-163.

Baudrillard, J. (2006). Passwords. From fragment to fragment. Ekaterinburg: UFaktoria, 240 p.

Baudrillard, J. (2006). Consumer Society. His myths and structures / J. Baudrillard. Moscow: Respublika.

Baudrillard, J. (2015). Simulacra and simulation / J. Baudrillard; transl. by A. Kachalova. Moscow: POSTUM.

Baudrillard, J. (2017). Fatal Strategies / J. Baudrillard; J. Baudrillard; transl. by A. Kachalova. Moscow: RIPOL-klasik.

Legacy of Jean Baudrillard School. Youtube channel of Expedition Journal. Retrieved from: Lesch, S. (2003). Sociology of postmodernism. Lviv: Kalvariia.

Maltsev, O.V., Lepskiy, M.A., Samsonov, O.V. (2019). Photography as a source of scientific information. Monograph. Dnipro: Serednyak T.K.

Kagan, MS (1974). Human Activity (Experience of System Analysis). Moscow: Politizdat.

Kurdyumov, SP, Samarskiy, AA (1989). Paradoxes of the multivariate world - the world around us. Hypotheses. Forecasts. Future of science. Intern. Yearbook. Moscow: Knowledge, 22. 13-22.

Popov, GS (1949). SRIM Archive (Memory SRI, by G. Popov) F. 3 ("Heritage of G. Popov" fund, Vienna 1940). Inv. 3, 1949 1. FC.1-7. 24 - 58. [Memory phenomenology: three Approaches to Study Memory. Manuscript] 
Szondi, L. (1956). Ich-Analyze. The foundation for the development of deep psychology. Part 1. - Bern: Hans Hube 